\title{
RAÍCES MITOLÓGICAS EN LA ICONOGRAFÍA DE LA BELLA DURMIENTE \\ EL CASO DE LA BELLA DURMIENTE DE WALT DISNEY
}

\section{MYTHOLOGICAL ROOTS IN THE ICONOGRAPHY OF THE SLEEPING BEAUTY \\ THE CASE OF WALT DISNEY'S SLEEPING BEAUTY}

\author{
Celia Ramiro Chulvi \\ Universitat de València, España \\ ceeliaramiro@gmail.com
}

Recibido: 07 febrero 2020 Aceptado: 10 marzo 2020

\begin{abstract}
Resumen: La Bella Durmiente es un cuento que todos podemos contar. Una princesa maldita que se pincha y cae en un profundo sueño hasta que su príncipe la despierta. Pero, como todas las historias, ha ido evolucionando hasta adquirir esta forma. Si rastreamos sus orígenes, la primera vez que fue plasmada en papel fue en el siglo XIII. Posteriormente, en el siglo XIV, se le suman tres versiones más. En el siglo XVII Giambattista Basile lo populariza, pero en ese mismo siglo Perrault lo adapta a su manera $\mathrm{y}$, en el siglo XIX, los hermanos Grimm lo simplifican.
\end{abstract}

A través de todas estas formas persiste una esencia, una narración común, unos elementos característicos que son los que permiten identificar este cuento como el mismo. $\mathrm{Y}$ en ellos podemos ver asomar los matices mitológicos, a veces en algo tan sutil como los nombres, y a veces en algo tan evidente como la presencia de un dios propio de la mitología.

Los cuentos han sido analizados desde diversas disciplinas: desde la lingüística, la antropología, la filosofía e incluso la religión, entre otros. En este artículo partiremos de dos metodologías claves: en primer lugar, aplicaremos la mitología comparada (cuyo principal representante es Max Müller) para comparar las diferentes versiones de los cuentos, así como los mitos con los que los relacionamos. Finalmente, acudiremos al método iconográfico de la Historia del Arte, atendiendo a las fuentes primarias para explicar la presencia de un icono o elemento en la obra artística analizada. 
Este es el procedimiento de este artículo: desglosar las fuentes primarias para comprender plenamente su presencia en el audiovisual de Walt Disney.

Palabras clave: Iconografía; Mitología; Cuentos; Disney; Durmiente

Abstract: Sleeping Beauty is a story we can all tell. A cursed princess who pricks herself and falls into a deep sleep until her prince wakes her up. But, like all stories, she has evolved into this form. If we trace its origins, the first time it was put down on paper was in the 13th century. Later, in the 14th century, three more versions were added. In the 17th century Giambattista Basile popularized it, but in that same century Perrault adapted it to his own way and in the 19th century the Brothers Grimm simplified it.

Through all these forms there remains an essence, a common narrative, some characteristic elements that allow us to identify this story as the same one. And in them we can see the mythological nuances appearing, sometimes in something as subtle as the names, and sometimes in something as evident as the presence of a mythological god.

The stories have been analyzed from different disciplines: from linguistics, anthropology, philosophy and even religion, among others. In this article we will start from two key methodologies: firstly, we will apply comparative mythology (whose main representative is Max Müller) to compare the different versions of the stories, as well as the myths with which we relate them. Finally, we will use the iconographic method of Art History, paying attention to the primary sources to explain the presence of an icon or element in the artistic work analyzed.

This is the procedure of this article: to break down the primary sources in order to fully understand their presence in the Walt Disney audiovisual.

Keywords: Iconography; Mythology; Fairytales; Disney; Sleeping

\section{INTRODUCCIÓN}

¿Dónde está la diferencia entre un cuento y un mito? Quizás pueden tener una diferente estructura o cronología, pero en esencia, son lo mismo. Narraciones. Tanto el cuento como el mito forman parte del folclore popular, es decir, del "saber tradicional del 
pueblo". En otras palabras, estas narraciones forman parte de una tradición que se ha transmitido oralmente a través de los siglos hasta ser plasmadas en papel.

Además, cada una de ellas pertenece a un momento y lugar concreto, a un pueblo, pero con la capacidad de poder ser adaptada según las necesidades de cada contexto. Esto genera una corriente creativa. El cuento, al igual que el mito, crece y cambia como si fuese un río que, al pasar en su recorrido por diferentes épocas y culturas, se adapta como el agua. Y, también como si fuesen ríos, estas narraciones se entremezclan y beben unas de otras, se reinventan, se complementan, se regeneran.

Los cuentos como expresión cultural han sido analizados en varios campos de estudio. Los mismísimos hermanos Grimm partieron desde el estudio de la gramática y la lingüística al comenzar a recopilar cuentos. También han sido estudiados desde la antropología, como en el caso de Vladimir Propp, que de igual manera comenzó un análisis lingüístico de los cuentos populares rusos y finalmente los observó desde un análisis antropológico como una narración esquemática, es decir, analizó los significados de un mismo esquema o elemento narrativo que se repite y de sus connotaciones sociales plasmadas en el folklore. Mircea Eliade, filósofo y religioso, construye un puente entre el mito y la religión como expresiones de lo sagrado. El método empleado por estos dos intelectuales es muy parecido a la mitología comparada. A grandes rasgos, Propp compara los cuentos con las tradiciones populares, mientras que Eliade compara la experiencia religiosa con la mitología. Max Müller, filólogo alemán, es fundador de la mitología comparada, una metodología que consiste en la comparación sistemática de mitos, respaldándose en sus similitudes lingüísticas para establecer conexiones.

En este artículo se parte de esta metodología: como se podrá observar, la comparación lingüística tiene cabida en la comparación de nombres desde la primera versión hasta la última. La mitología comparativa es usada aquí con un nuevo enfoque: no solo comparamos mitos, si no mitos y cuentos, al ser considerados en este artículo como equivalentes. 
La estrecha relación del mito y el cuento ha sido establecida en diversos estudios. El antropólogo argentino Adolfo Combres define con precisión la línea que conecta ambas tipologías (COLOMBRES, Adolfo, 1997, p. 242):

"El mito, en tanto estructura con un significado, puede desplegarse de un modo u otro en cualquier género, aunque en tanto relato conforma un género aparte, asociado a la leyenda y el cuento por algunas similitudes. Pero mientras el cuento configura en todos los casos una ficción reconocida como tal por los narradores y receptores, el mito es vivenciado como un relato sagrado."

En su artículo, Colombres define el mito como un reflejo distorsionado del mundo real al que las personas acuden en busca de respuestas a sus preguntas primordiales. El mito es antiguo, parte de las sociedades iniciales y surge en base a inquietudes filosóficas y antropológicas. Los cuentos, por su parte, no participan de lo sagrado y son menos complejos, además de ser concebido como ficción. Las estructuras correspondientes a los cuentos han sido estudiadas por Vladimir Propp y en el método Aarne-Thompson, entre otros.

Otro autor clave para el desarrollo de este artículo ha sido Graham Anderson y su obra Fairytale in the ancient world, en la que busca exhaustivamente las primeras versiones de los cuentos. (ANDERSON, Graham, 2000, p. 10):

“Gran parte del tiempo uno se siente como el príncipe que busca entre la maleza el castillo encantado de la Bella Durmiente. Pero el placer es igual a la dificultad que supone la tarea: cuando la maleza se ha despejado, encontramos un castillo lleno de Blancanieves y Cenicienta, Rumpelstiltskin y el resto, en la misma habitación. Lo más apasionante: todos ellos han estado allí no solo por cientos de años; en algunos casos durante miles. Y algunas partes de ese castillo no son medievales, si no construidas con columnas clásicas o incluso fundaciones más tempranas."

Finalmente, la metodología que enlaza todo esto con la Historia del Arte es el método iconográfico-iconológico en el que se acuden a las fuentes primarias para revelar la presencia de un icono y su significación. En este artículo hemos acudido a dichas 
fuentes y las hemos comparado entre sí, para justificar finalmente la presencia de ciertos elementos en el audiovisual escogido.

La elección del cuento de la Bella Durmiente y su audiovisual responde a una simple pregunta: ¿de dónde sale el dragón? Al no encontrarlo en las versiones populares, la cuestión de la aparición de un dragón en el audiovisual de Disney parecía digno de estudio. ¿Responde a una voluntad de introducir un elemento del imaginario popular sobre los cuentos de hadas y el medievo o, por el contrario, es fiel a fuentes menos conocidas sobre el cuento?

A continuación, veremos las diferentes versiones de La Bella Durmiente, desde la más temprana cronología hasta las versiones populares. En los apartados siguientes veremos la influencia mitológica (explícita o no) y su traducción en la iconografía empleada en la película La Bella Durmiente.

\section{EL CUENTO: SUS DIFERENTES FORMAS}

Retomando lo comentado en el apartado anterior, debemos tener en consideración el método Aarne-Thompson o ATU, sistema de clasificación de cuentos de hadas. En el ATU, la Bella Durmiente corresponde a la numeración 410, es decir: cuento folclórico ordinario, cuento de magia, esposo/a o pariente encantado. La clasificación AarneThompson, considerada la más completa, delimita cinco grandes tipologías: cuento de animales, cuento folclórico ordinario, cuento humorístico, cuento de fórmula y cuentos no clasificables. Esta tabla fue criticada por Vladimir Propp, también experto en cuentos, que para delimitarlos usó las llamadas "funciones", es decir, 31 motivos que se repiten en la mayoría de cuentos, como por ejemplo la huida del protagonista, la gesta, etc.

Una vez comprendido el cuento en su complejidad, será más fácil comprender la pervivencia de un mismo cuento a través de diferentes autores. La Bella Durmiente, en todas las variables que ahora veremos, presenta elementos en común que son los que permiten relacionarlos, ya sean las mismas funciones según Propp o el mismo esquema según el ATU. 


\section{Brynhild en la Saga Völsunga}

La primera fuente escrita con una narración cuyo esquema corresponde al cuento la encontramos en la nórdica Saga Völsunga. Por tanto, la primera aparición de la princesa del cuento es en una fuente mitológica, lo cual refuerza esta idea de unificación entre mitos y cuentos.

Brunilda es una valquiria, que, mandada por el dios Odín a intervenir en la lucha entre dos reyes, se declina a favor del contrario a Odín. Esto le vale el castigo del sueño mortal y la reclusión. Es interesante saber que Odín la duerme pinchándola con una espina. El héroe Sigurd, el héroe de El cantar de los nibelungos (también llamado Siegfried), accede a esta torre donde la princesa es custodiada por un anillo de fuego y por un dragón, y tras vencer ambos obstáculos, la despierta.

Odín, dios principal del panteón nórdico, posee dos cuervos que representan sus ojos. Estos cuervos, Hugin y Munin, observan el mundo por él y le llevan noticias. Esto es muy importante y lo veremos en el apartado dedicado a la iconografía.

\section{Zellandine y Troylus en Perceforest. 1340 (S.XIV)}

La historia de Zellandine y Troylus pertenece a un texto francés llamado Perceforest, compuesto hacia el año 1340. Este texto forma parte de la materia de Bretaña y se divide en varios libros, de los cuales el tercero cuenta la historia de Zellandine. Cuando nace, las diosas Venus, Lucina y Temis asisten al convite, pero Temis entra en cólera al ver que no le habían puesto cubiertos y maldice a la niña con la muerte al pincharse con una astilla. Venus reduce el castigo a un sueño eterno que se puede curar al quitarle la astilla.

Zellandine crece y conoce a Troylus, un caballero del cual se enamora, pero él tiene que probar su valía para desposarla. Mientras él realiza estas gestas, la maldición se cumple y Zellandine es prisionera de un sueño eterno. La depositan en una torre inaccesible, pero Troylus vuelve de sus gestas y gracias a un pájaro sube a la torre. Allí, incapaz de despertarla, mantiene relaciones sexuales con ella, dejándola embarazada. Al 
nacer, el niño busca mamar de su madre y acaba chupándole el dedo con tanta fuerza que le extrae la astilla.

\section{Poemas occitano-catalanes del siglo XIV.}

Las otras dos narraciones tienen un marco común: son poemas occitano-catalanes. El primero de estos poemas se titula Blandín de Cornualles, y cuenta la historia de Brianda, una joven que es inducida a un sueño eterno por su padre y custodiada en un castillo por diez caballeros, una serpiente y un dragón. Tras vencerlos a todos, Blandín despierta a la princesa con la ayuda de un pájaro. El segundo se titula Frayre de Joy e Sor de Plaser, que se traduce como Hermano de Alegría y Hermana de Placer (el príncipe y la princesa, respectivamente). La princesa cae en un sueño eterno repentinamente y su padre la deposita en una torre inaccesible, pero el príncipe consigue entrar. Allí toma sexualmente a la princesa, que al cabo de nueve meses alumbra a su hijo. Tiempo después, un pájaro deposita hierbas en su mano y la despierta.

\section{El cuento de los cuentos. Giambattista Basile. 1634.}

Sol, Luna y Talía, de Giambattista Basile, cuenta la historia que ahora conocemos como La Bella Durmiente, pero que en esta narración se llama Talía. Al nacer la princesa, los reyes consultan a los adivinos del reino, quienes avecinan que sufrirá una desgracia mortal causada por una espina de lino. Se prohíbe en el reino el uso de lino, pero un día una anciana postrada frente al castillo comienza a hilar con una rueca y un huso, lo cual atrae la atención de la pequeña Talía. Al tocar el objeto, se le clava una espina de lino en la uña y cae en un sueño eterno. Instalan a la princesa dormida en un castillo.

Pasa el tiempo y un rey que cazaba por esas tierras descubre aquel palacio cuando su halcón se cuela por una ventana. Entra a recuperarlo y ve a la hermosa princesa, así que decide violarla. Fruto de ese abuso, Talía queda encinta y nueve meses después nacen los gemelos Luna y Sol. Compasivas, dos hadas cuidan de ellos hasta que un día, buscando desesperadamente algo que mamar, los niños chupan el dedo de su madre con tanta fuerza que extraen la espina y la devuelven a la vida. Talía y sus hijos se quedan a vivir en ese castillo. 
Tiempo después, el rey vuelve a pasar por allí y decide entrar al castillo, encontrando a la princesa despierta y con las dos criaturas. Los lleva a su reino, pero el rey ya estaba casado y la reina (esposa del rey) enfurece. Celosa, demanda al cocinero que mate a los niños y se los sirva al rey para comer, pero el cocinero se compadece y esconde a los niños, cocinando a dos cabritillos en su lugar. Tras esa comida, la reina se propone quemar a Talía en una hoguera, pero el rey la descubre y la salva. Como castigo, queman a la reina en la hoguera.

\section{Los cuentos de mamá Oca. Charles Perrault. 1697.}

En la versión de Perrault surge la denominación "bella durmiente", pues el título del cuento es La bella durmiente del bosque. Cuenta cómo al nacer la princesa los reyes celebran una gran fiesta e invitan a las siete hadas, olvidándose de invitar a un hada vieja a la que creían muerta porque llevaba 50 años viviendo como una ermitaña. El hada, ofendida, maldice a la niña a morir al pincharse la mano con un huso, pero una de las hadas reduce el castigo a dormir durante 100 años al pincharse. Los reyes prohíben el uso de las ruecas. Quince años después, una amable anciana estaba en un torreón del castillo hilando en huso porque no se había enterado de la prohibición.

La princesa se pincha y cae en un profundo sueño. Años después, un príncipe la visita y, enamorada, la princesa despierta con su sola presencia. Intiman y el fruto de ese amor son los gemelos Aurora y Día. Todos se trasladan a vivir al palacio del príncipe, pero su madre, la reina, quiere a su hijo para ella sola. Encarga al cocinero que los cocine en una cuba con sapos y culebras para comérselos ella misma. Entonces aparece el príncipe y la lanza a esa misma cuba, causándole la muerte.

\section{Cuentos para la infancia y el hogar. Jacob y Wilhelm Grimm. 1812.}

En el caso de la versión de los Grimm, el nombre que recibe el cuento de la Bella Durmiente es La pequeña Briar-Rose o La espina de la rosa.

Los reyes tuvieron una niña y al nacer, celebraron una gran fiesta. Querían invitar a todo el reino, incluidas las trece hadas, pero como solo tenían doce cubiertos de oro, no 
invitaron a una. Aparece el hada no invitada y maldice a la niña con morir pinchada por un huso, y la última de las hadas minimiza la maldición a dormir durante 100 años. Se prohíben los husos pero al cumplir la niña quince años, paseando por el castillo, encontró a una ancianita en lo alto de una torre que estaba hilando con una rueca, pues llevaba tanto tiempo allí que no se había enterado de la prohibición. Al acercarse, la princesa se pinchó, durmiéndose, y también todos los miembros del castillo se durmieron.

Creció un zarzal que cubría completamente el castillo. Muchos príncipes intentaban penetrar en las zarzas para llegar a la princesa, pero morían en el intento. Sin embargo, el día que se cumplía un siglo de la desgracia, llegó un príncipe que al intentar entrar al castillo encontró que las zarzas se habían trasformado en preciosos rosales. Llegó a la estancia de la princesa, la besó y se despertó, despertando acto seguido el resto de la corte.

\section{RAÍCES MITOLÓGICAS}

En algunas versiones primordiales de la historia, hemos visto personajes mitológicos clave para el posterior desarrollo: la diosa Venus, cuya presencia se transforma en el concepto de belleza otorgado como regalo a la princesa en el día de su nacimiento, y el dios Odín, que es el enemigo inicial de la protagonista, así como Temis, diosa de la justicia.

De estos relatos se pueden extraer también otras implicaciones mitológicas, desde aspectos más amplios a otros más concretos. Comencemos por el contexto de la localización.

Gran parte de la historia ocurre en el bosque, especialmente en el audiovisual de Disney que analizaremos posteriormente. El bosque es el entorno clave porque en la Antigüedad suponía el lugar donde se llevaban a cabo los rituales iniciáticos. Era el punto de partida para la iniciación ligada a la edad adulta. Por ello, no es casualidad que para llegar a su "madurez" (tanto física como narrativa) la protagonista esté limitada por los confines de un bosque, y solo al salir de allí tenga lugar su nueva vida. Como afirma Vladimir Propp: 
"El bosque circunda al otro mundo, el camino para el otro mundo pasa por el bosque. (...) La mayor parte de las entradas al mundo subterráneo estaban rodeadas por una impenetrable selva virgen o bosque. Este bosque era un elemento constante en la representación ideal de la entrada al Hades (...) Estos materiales permiten formular la siguiente conclusión: el bosque del cuento maravilloso refleja por un lado la reminiscencia del bosque, como lugar donde se celebraba el rito y, por otro lado, como entrada al reino de los muertos. Ambas representaciones están estrechamente ligadas entre sí.” (Propp, 2008, pp.78-79)

Por tanto, el punto de partida de los cuentos de hadas es el bosque por su doble función como espacio ritual y como punto limítrofe entre la vida y la muerte. Esto es evidente en La Bella Durmiente. El bosque es el espacio en el que tiene lugar el viaje mistérico, que prepara para una nueva etapa. Es un espacio de transición entre la vida y la juventud, y el sueño mortal que deja a la protagonista prácticamente en un estado inerte.

Pasemos ahora a referencias mitológicas concretas. Comenzando el análisis desde la versión de Basile, la joven protagonista Talía da a luz a unos gemelos llamados Sol y Luna, que en la posterior versión de Perrault serán Aurora y Día. Hay un mito clásico del nacimiento de los gemelos Sol y Luna: la historia de Leto y el parto de sus hijos Apolo y Artemisa, dioses del sol y la luna respectivamente. Leto había tenido relaciones sexuales con Zeus. Iracunda, su esposa Hera sentenció que no podría dar a luz allá donde alcanzasen rayos del sol. Con ayuda de los dioses, Leto logró finalmente dar a luz a los gemelos. Esta historia presenta varios elementos que vemos en el cuento: una princesa que mantiene una relación extramatrimonial, da a luz a dos hijos que encarnan respectivamente el Sol y la Luna, y es perseguida por la mujer legítima de su amado.

Apolo y Artemisa encarnan el papel del sol y de la luna, por tanto su presencia indica el ciclo completo de un día. El nombre de los gemelos evolucionará en la versión de Perrault a Día y Aurora, centrándose más en el nacimiento como la puerta a un nuevo día o comienzo. Posteriormente, debido al ballet de Tchaikovski, el nombre de Aurora se traspasará de la hija a la madre, relegando así el original Talía. En la Antigüedad Clásica este nombre, Talía, bautizaba a la musa del teatro cómico, que como el resto de las musas 
formaba parte del séquito de Apolo. Volvemos a ver que este hecho está íntimamente relacionado con el dios del Sol.

Además, Talía viene del griego $\Theta \alpha ́ \lambda \varepsilon ı \alpha$, «floreciente», lo cual es relevante dado que en la versión de los hermanos Grimm se la llamará Briar Rose, cuya traducción significaría "la rosa con espinas" o "la rosa de la zarza". Por tanto, vemos una conexión entre el nombre de la protagonista y las flores. Esto nos remite a las naturalezas habitadas por lo femenino. La mitología griega tiene numerosas mujeres que son espíritus florales o simplemente acaban habitando un espacio natural, como por ejemplo las ninfas y las náyades, o Dafne y Mirra. Dafne era una ninfa que fue perseguida precisamente por Apolo, y para salvarse de ser violada, fue convertida por los dioses en el árbol del laurel.

Por otra parte, el nombre de Aurora en la mitología griega alude a una diosa que personifica el comienzo del día, y que, además, es hermana de Apolo y Artemisa. Por lo tanto, el Sol y la Luna se triangulan con una tercera integrante (bien su madre, bien su hermana, bien su esposa) que completa esta tríada de la jornada diaria.

En la versión del siglo XVI, titulada Perceforest, se nos dice que al nacimiento se invita a las diosas Venys y Lucina, pero no a la diosa Temis, que al aparecer allí y ver que no tiene cubiertos maldice a la niña con la muerte. Este esquema de una diosa/hada que no ha sido invitada y desata su furia se repite en gran parte de las versiones. Las tres diosas mencionadas en el relato pertenecen a la mitología romana: Venus es Afrodita, diosa del amor y la belleza, Lucina es la diosa de los partos y Temis es la diosa de la justicia. La ira por no haber sido invitada provocará consecuencias que se mantienen en las diversas versiones de La Bella Durmiente. Pensemos en el episodio de la Manzana de la Discordia como un claro antecedente de esta situación. En dicho episodio mitológico, se celebraba la boda de Peleo y Tetis, que olvidan invitar a Eris, diosa de la discordia. Al verse excluida, Eris decide sembrar el caos con una manzana dorada del Jardín de las Hespérides, y todo ello derivará finalmente en la Guerra de Troya.

Por lo tanto, vemos aquí este patrón de una mujer poderosa enfadad por no ser invitada que lanza una maldición. El hada vieja que maldice a la niña con la muerte puede ser una evolución del arquetipo de Eris. Y al hilo de ello, no es casualidad que la 
maldición que recae sobre la joven princesa sea morir pinchada con una rueca. Está determinado que su destino va hilado a la rueca, y que inevitablemente sucederá. Cuando llega el momento de cumplir su destino, es una anciana la que sujeta la rueca. Esta conexión de una anciana con una rueca y con el destino, tiene ecos en las cosmovisiones y relatos mitológicos. En primer lugar, cabe citar a las moiras de origen griego, que posteriormente encarnarán a las parcas, esto es, tres mujeres que manejan el hilo del destino y que deciden sobre la vida de cada hombre. Cada una de ellas decidían el nacimiento (Cleto), vida (Láquesis) y muerte (Atropos) de cada ser manejando el hilo de su vida. Son mujeres hilanderas, en algunas versiones las tres son ancianas y en otras versiones cada una tiene una edad, encarnando así la juventud, la madurez y la vejez. Estas tres entidades femeninas también tienen un equivalente nórdico, las Nornas, que habitan en las raíces del árbol del mundo, conocido como Yggdrasil, desde donde deciden sobre el destino de los hombres.

Concluimos, entonces, que esta mujer hilandera del cuento que induce a la princesa en un sueño mortal es una derivación de las parcas (o incluso una parca en sí) y que su relación con el destino es más que evidente.

Aún más interesante si cabe es el dato de que las parcas eran precisamente hijas de Temis, la diosa de la justicia que en la versión de Perceforest no era invitada. Por tanto la evidencia de que la hilandera del cuento es una parca o una moira queda reforzada con la aparición de su madre, diosa de la justicia, en una narración previa. El papel ejercido por Temis en el relato medieval será el que luego recaiga sobre el hada no invitada e, indirectamente, en la hilandera (no necesariamente malvada) que la princesa encontrará en el castillo. Solo con esta aparición de la hilandera como personificación del destino ya se puede relacionar el cuento con tres tradiciones mitológicas: la griega, la romana y la nórdica.

\section{ICONOGRAFÍA: PELÍCULA DISNEY}

La filmografía Disney ha sido objeto de muchos estudios de diversas disciplinas, al igual que el cuento: antropología, feminismo, política, religión, etcétera. En el caso de La Bella Durmiente, y desde la perspectiva que aborda este artículo, cabe destacar el libro Once 
Upon a Dream: from Perrault's Sleeping Beauty to Disney's Maleficent de Charles Solomon, que estudia la evolución de la narración desde la versión popular de Perrault hasta la actualidad.

En este caso, no solo vamos a ver la evolución de la historia desde la versión popular, sino también la justificada presencia de las raíces mitológicas y cómo estas afectan no solo a la narración si no a la iconografía empleada en el audiovisual.

Vamos a analizar la película La Bella Durmiente, obra de Walt Disney en 1959. Esta producción cinematográfica informa en sus créditos iniciales que el texto de referencia en la película es la versión de Charles Perrault aunque la película es una interpretación, y que la música es, igualmente, reinterpretación del ballet de Tchaikovski.. Pese a decir que la referencia principal es Perrault, veremos que están presente elementos de todas las versiones e, incluso, de las raíces mitológicas.

Comienza la película con el nacimiento de la recién nacida. Durante la celebración en palacio aparece el hada no invitada, encarnada por la original Maléfica que maldice a la niña con pincharse con una rueca, objeto que ya sabemos que remite a las parcas y, por tanto, al destino. La niña, llamada en esta versión Aurora (manteniendo así un nombre mitológico), es tomada por tres hadas buenas para ser criada en el bosque, y más exactamente dentro de un árbol, que materializa la idea del árbol habitado. [1]

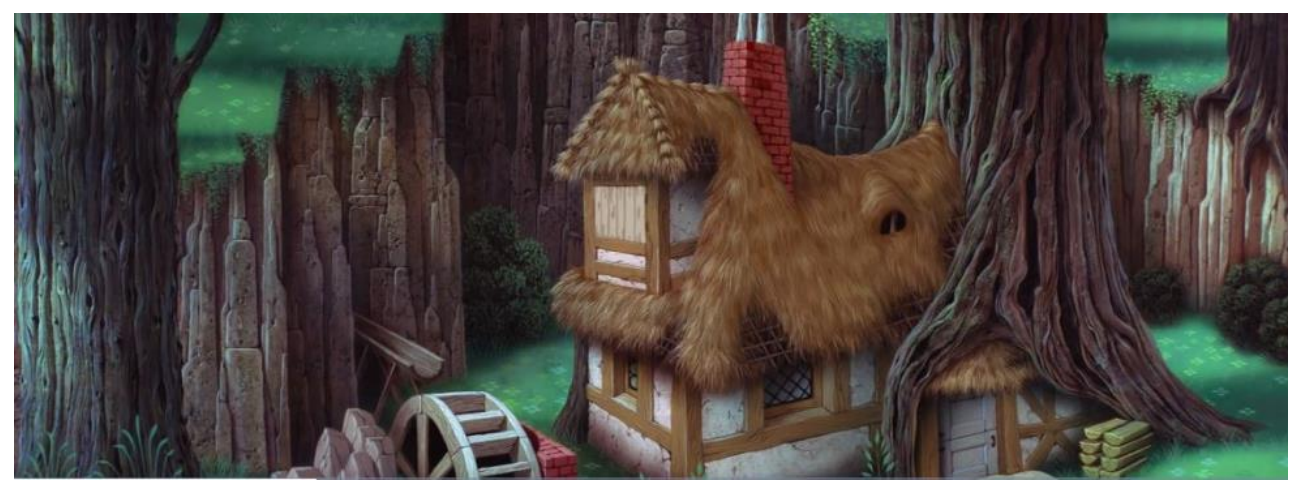

1. Casa-árbol en el bosque, Sleeping Beauty, Walt Disney Pictures, 1959 
Esto nos recuerda al mito de Dafne. De hecho, la primera solución que propone el hada Flora para librar a la princesa de la maldición es convertirla en una flor. También vemos una referencia mitológica en el minuto 29:08, cuando el príncipe oye a Aurora cantar y piensa que es una ninfa del bosque. Finalmente, es clave que las hadas renombran a la niña como Rosa, influencia directa de la versión de los hermanos Grimm, Briar Rose.

Aurora crece en el bosque y es allí donde la encuentra el príncipe, a quien confiesa haber conocido previamente en un sueño. Esto es una alusión a las versiones del cuento en las que el príncipe toma sexualmente a la princesa mientras duerme. Ambos cantan sobre dicho encuentro en la canción Once upon a dream. Que el príncipe penetre en el bosque, espacio esencialmente femenino, se relaciona con la idea del bosque como espacio de tránsito y espacio sagrado. [2]

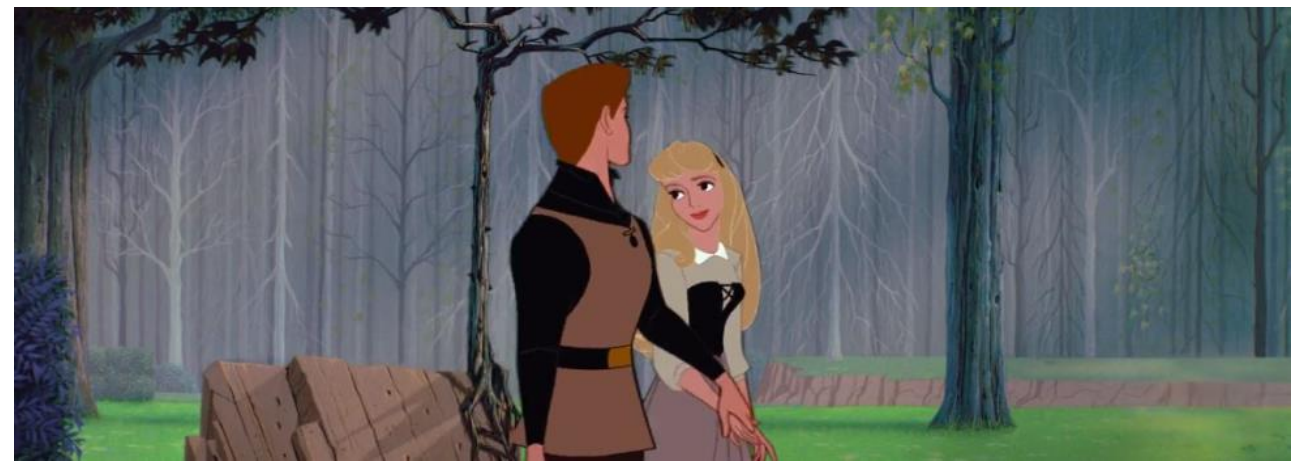

2. Encuentro en el bosque, Sleeping Beauty, Walt Disney Pictures, 1959

El fiel cuervo de Maléfica, Diablo, encuentra a la princesa. [3] [4] Que la enemiga de la princesa tenga como siervo a un cuervo que peina los bosques observando lo que sucede y contándoselo luego, es una adaptación de la presencia de Odín en el mito nórdico de Brunhild. Diablo sería una versión de Hugin y Munin.

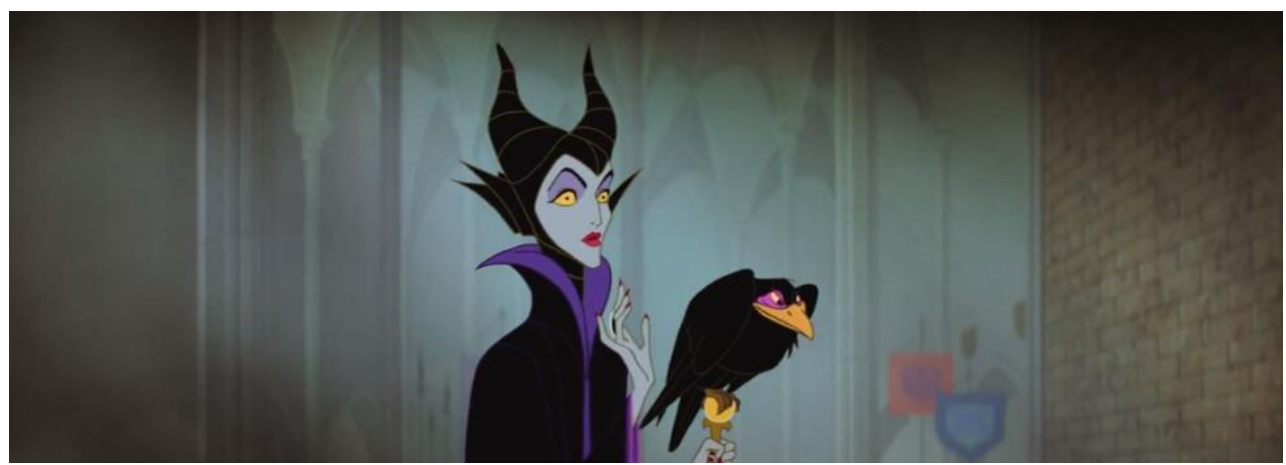

3. Maléfica y Diablo, su cuervo, Sleeping Beauty, Walt Disney Pictures, 1959 


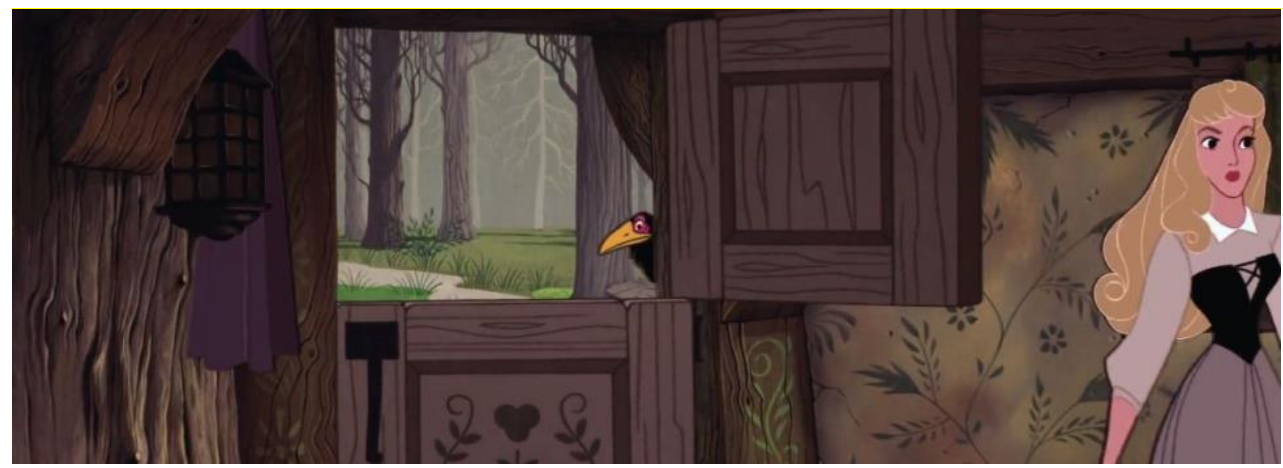

4. Diablo espiando a la princesa, Sleeping Beauty, Walt Disney Pictures, 1959

Maléfica la hechiza y hace que se pinche con la rueca, cayendo en el sueño mortal. Al igual que en la versión de los hermanos Grimm, todos los habitantes del castillo se duermen y sobre él crece una densa zarza. En este caso, la zarza la genera Maléfica para evitar que el príncipe pase. Cuando consigue atravesarla, la villana se transforma en dragón y se enfrenta directamente a él. [5] No figura ningún dragón en la versión de Perrault, y tampoco en la de los Grimm, pero ya hemos visto que efectivamente sí hay un dragón en el mito nórdico de Sigmund y Brunilda y en el poema occitano de Blandín de Cornualles. Una vez vence y alcanza a la princesa, la despierta con un beso, tal y como sucede en la versión de los Grimm.

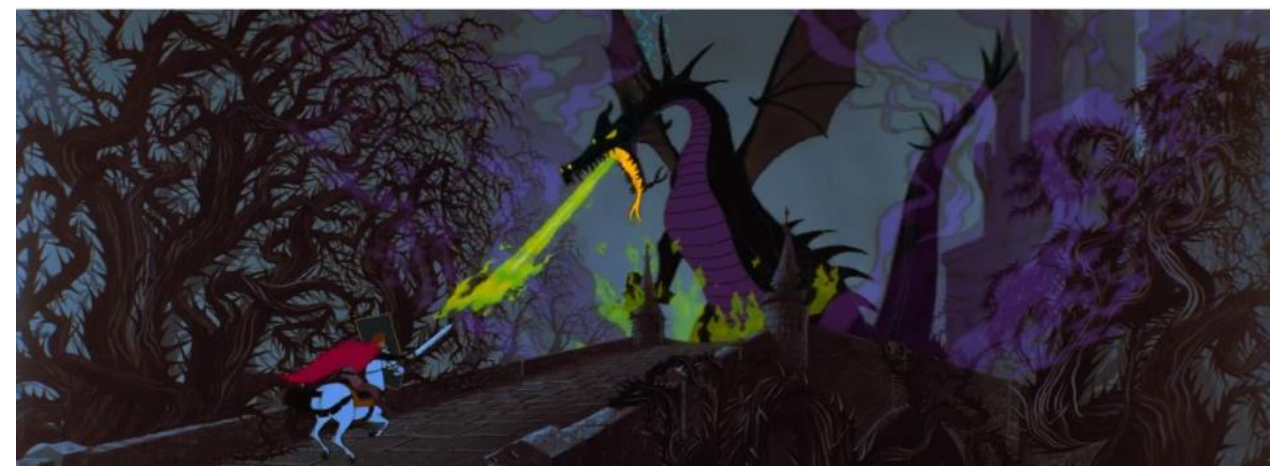

5. Maléfica convertida en dragon. Sleeping Beauty, Walt Disney Pictures, 1959

\section{CONCLUSIÓN}

La mitología y los cuentos de hadas son una buena combinación como caso de estudio en muchas disciplinas, principalmente del antropocentrismo y del lenguaje, tal y como hemos visto. Si bien a veces los autores discrepan en ciertos matices, el estudio de eruditos como Mircea Eliade, Vladimir Propp, o el caso Aarne-Thompson, nos permiten 
delimitar la sutil diferencia entre cuento y mito, pero también ponerlos en la misma mesa como ramificaciones de un mismo árbol.

En este artículo hemos abordado esta relación desde la Historia del Arte, tomando como referente el audiovisual y tornando la vista en retrospectiva para justificar la presencia de elementos concretos. Aún más: hemos establecido un nuevo puente que difiere sutilmente de los mencionados previamente. Si bien coincidimos en la diferenciación de cuento y mito, hemos demostrado que algunos esquemas o aspectos pueden reinventarse y fluir del mito al cuento o viceversa, creando una nueva conversación y difuminando los límites de separación.

La película La Bella Durmiente de Walt Disney aúna en una única historia elementos de todas las narraciones que han ayudado a constituir el cuento. La presencia de un dragón o un anillo de fuego solo podemos referenciarla en los poemas de Blandín de Cornualles y en la Saga Völsunga. El cuervo como “ojos", de nuevo, es una clara alusión al papel de Odín en la narración. Esto demuestra que la compañía cinematográfica conocía dichas versiones, quizás directamente a través de las fuentes primarias, quizás por tradición oral.

En cualquier caso, queda perpetuada esta raíz mitológica presente en el germen del cuento, que actualmente otorga algunos de los aspectos clave de la historia como son el dragón o la configuración final de la figura de Maléfica. Su evolución desde un origen mitológico hacia el cuento final responde a pulsiones antropológicas y sociales propias de cada sociedad que ha revivido esta narración para sus propias finalidades.

\section{RECURSOS BIBLIOGRÁFICOS}

Anderson, Graham (2000) Fairytale in the ancient world. Routledge: London.

Basile, Giambattista (2006). Pentamerón o El cuento de los cuentos. Editorial Siruela: Madrid.

Bonavides, Enrique (1999). “Artemisa o el enigma de los límites" en COHEN, Esther (dir). De filósofos, magos y brujas. Barcelona, Azul Editorial, pp.12-16. 
Bernárdez, Enrique (2018). Mitología nórdica. Alianza Editorial: Madrid.

Colombres, Adolfo (1997). Celebración del lenguaje. Ediciones del Sol: Argentina.

Eliade, Mircea (2003). Mito y realidad. Editorial Kairós: Barcelona.

Grimm, Jacob; Grimm, Wilhelm (2015). Cuentos completos 1. Alianza Editorial: Madrid.

Hernández de la Fuente, David (2015). Mitología clásica. Alianza Editorial: Madrid.

Perrault, Charles (2016). Cuentos completos. Alianza Editorial: Madrid.

Propp, Vladimir (2008). Las raíces históricas del cuento. Fundamentos: Madrid.

\section{Grabaciones musicales o películas}

Disney, Walt; Geromini, Clyde (dir.). (1959) Sleeping Beauty. USA, Walt Disney Pictures (75min.) [película]. https://www.imdb.com/title/tt0053285/ 